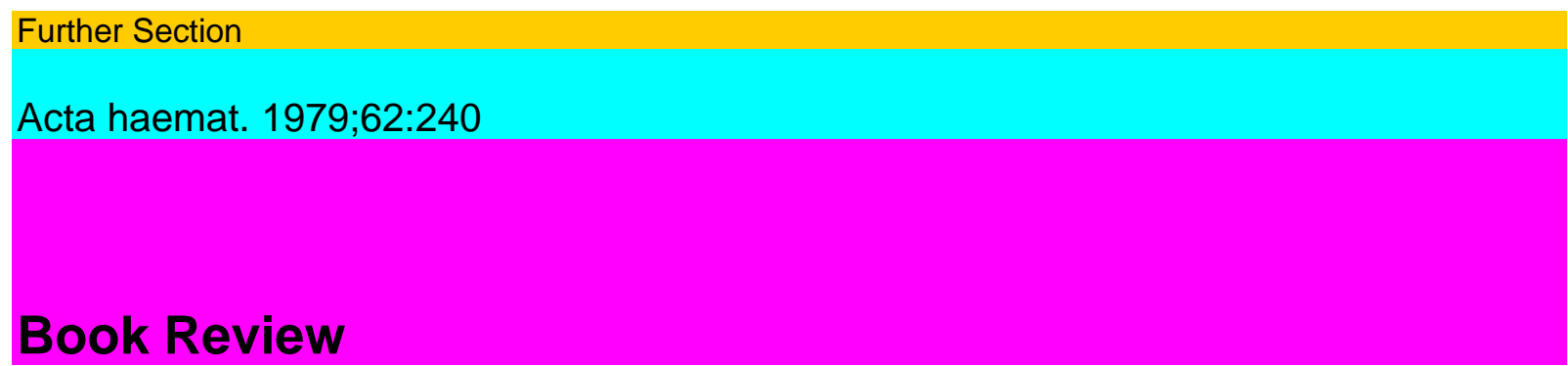

\title{
A.F.W. Morselt
}

Applications and Possibilities of

Cytophotometry for Red Cell Hematology

Progress in Histochemistry and Cytochemistry,

Vol. 11, No. 3

Fischer, Stuttgart 1978

VI + 42 pp., 28 tab.; DM 36.-

ISBN 3-437-10557-4

Die kurze Monographic fasst die Ergebnisse langjähriger, technisch aufwendiger

Untersuchungen knapp und klar zusammen. Bei oberflächlicher Betrachtung mag es scheinen, als ob nur ein kleiner Kreis von Spezialisten angesprochen werde. Ver-tieft man sich in Morselts Werk, wird bald einmal deutlich, dass es hier um eine Reihe von grund-legenden Fragen der Erythropoese geht, die jeden Hämatologen und wohl auch weitere Kreise inter-essieren dürften. Es geht dem Autor darum, auf Möglichkeiten der mikrospektrophotometrischenMessung(= Messung des Absorptionsspektrums an einem Punkt) und zytophotometrischen Messung (= Integration der totalen über einer Zelle oder einer Zellorga-nelle bei bestimmter Wellenlänge gemessenen Ex-tinktion) von Erythrozyten oder hämoglobin-haltigen Zellen des Menschen hinzuweisen. Ver-schiedene Fragen liessen sich durch mikrospektro-photometrische Untersuchungen an Erythrozyten beantworten: Einfluss verschiedenartiger Fixa-tionen auf das Spektrum des Hämoglobins, Ver-gleich der Spektren von Erythrozyten von Erwach-senen und Neugeborenen, Ablauf der Malaria-Pigmentbildung in befallenen Erythrozyten, Abbau des Hämoglobins phagozytierter Erythrozyten zu Hämosiderin und Bilirubin in Makrophagen, Extinktionen elektronenoptisch definierter Strukturen

und Vergleich der Absorptionsspektren des Hämoglobins und anderer Farbstoffe in Lösung und in Gewebe.

Zytophotometrische Bestimmungen des Hämo-globingehaltes einzelner Erythrozyten erlaubten, den Effekt einer Eisentherapie bei einer Eisenman-gelanämie anhand der

Hämoglobingehaltvertei-lung präzis zu verfolgen sowie den relativen Ge-halt von $\mathrm{HbF}$ in einem einzelnen Erythrozyten zu bestimmen und zudem die Wirkung der Elution zu verfolgen.

Durch gleichzeitige zytophotometrische Be-stimmung des Hämoglobingehaltes und der Projektionsfläche einzelner Erythrozyten in Erythro-zytenpopulationen bekannten Alters konnte gezeigt werden, dass bei Erythrozyten mit vergleichbarem Hämoglobingehalt die Projektionsfläche mit zu-nehmendem Alter abnimmt. Durch Verwendung von Brillant Cresyl Blau und Messung bei 580 und 416 nm konnte gezeigt werden, dass bei einer Eisenmangelanämie nach Eisenzufuhr der Hämoglobingehalt der im Blut zirkulierenden Retikulozyten zwischen dem 3. und 5. Tag um etwa 40\% zu-nimmt. Mit der gleichen Methode wurde gefunden, dass polychromatische Normoblasten rund doppelt soviel RNS, aber fast gleich viel Hämoglobin ent-halten wie azidophile. Durch kombinierte zytophotometrische Bestimmungen des Hämoglobin- und DNS-Gehaltes einzelner Erythrozytenvorläufer verschiedener Reifegrade 
konnte schliesslich die Klassifizierung der kongenitalen dyserythropoeti-schen Anämie erleichtert werden.

Gesamthaft betrachtet, vermittelt die Mono-

graphie eine sehr wertvolle Übersicht über die viel-

fältigen Anwendungsmöglichkeiten mikrospektro-

photometrischer und zyctophotometrischer Metho-

den in der Hämatologie. $\quad$ H. P. Wagner, Bern 